produce two part-time posts thereby broadening the variety of clinical approach and supervision available.

The pattern in most provincial centres has been for whole-time or maximum part-time appointments. The duties of some of these appointments have been peripatetic with the post holder making regular visits to several centres in a Region, but having a principal base. Often the consultant will be working alone or with one colleague and will therefore need to devote a significant proportion of time to building up the psychotherapy service. It is important that the consultant's duties are not so diverse nor the sessions so dispersed that the essential role of establishing a viable psychotherapy presence is inhibited. Linking the peripatetic or isolated consultant to an established psychotherapy centre will help maintain professional morale and assist recruitment.

Particular care should be taken to safeguard the position of 'Consultant Psychiatrists with special resonsibility for Psychotherapy'. These posts may be proposed when the Authority has not got the resources for a full-time post or is uncertain that it wants to commit that level of resource to psychotherapy. These posts often prove unsatisfactory as there is insufficient time to perform either portion of the job to a high standard. In these posts the majority of the sessions should be allocated to psychotherapy, i.e. at least six out of 11 sessions. It should be made plain that the primary responsibility of the consultant is to psychotherapy. The duties required in the remaining sessions should not be such as to erode the psychotherapy time. Circumscribed responsibility for a day centre, ward, liaison service or limited general psychiatry would be appropriate in the non-psychotherapy sessions. The Section would prefer to see the development of consultant psychotherapy posts with a special interest in a variant of psychotherapy, e.g. group or family work, or day hospital or therapeutic community. Special interest posts with a minority interest (less than 50 per cent of sessions) in psychotherapy are not an acceptable substitute for consultant psychotherapist posts.

\section{Psychotherapy sessions}

The first duty of the consultant psychotherapist, like any other consultant in the National Health Service, must be to those patients for whom he or she carries direct or indirect clinical responsibility. It is impractical for the consultant to attempt to meet in person all the needs for psychotherapeutic treatment in his or her area. The best way of achieving this objective is by developing the practice of psychotherapy skills at generalist and specialist levels by training and supervision of psychiatrists and nonpsychiatrists. The consultant has a prime role in developing, co-ordinating and encouraging the psycho- therapy practice of psychiatrists and other professionals with similar interests.

For the sake of his or her professional standing and development the consultant should have a sufficient number of clinical sessions; these should be used for making assessments and practising psychotherapy. In a full-time post a reasonable division would be five sessions for supervision and teaching, four for clinical work and two for administration, research and travelling. For a special responsibility post with six sessions of psychotherapy it would be reasonable to divide the time equally between clinical work and teaching.

The Psychotherapy Section considers it to be of the utmost importance that a whole-time secretary be provided to assist with the work of each full-time or special interest consultant. Without the means to communicate and organize the teaching and clinical service, the consultant is severely handicapped.

Some indication that junior medical support will be forthcoming should be made. This might take the form of senior registrar elective sessions or a rotating experienced registrar, perhaps working half-time in psychotherapy for a year at a time. Trainees make a valuable contribution to providing the clinical services.

A consultant with clinical responsibility beyond making assessments will need the help of colleagues willing or able to undertake the therapy of some of the patients referred for treatment. Such assistance might come from trainee psychiatrists who acquire their supervised cases from a waiting list maintained by the consultant or from designated sessions from various staff for the psychotherapy service. Clinical assistants, social workers, psychologists, occupational therapists and nurses with an aptitude for psychotherapy and working, preferably full time, for the psychotherapy service are of great value. In providing an out-patient service, the minimum requirement is for one full-time co-worker drawn from one of the above disciplines in addition to the consultant. The requirement for further staff would depend upon the extent of the i service needed in a particular District. If the consultant is to have responsibility for a psychotherapy day centre or inpatient unit, assurances should be given that adequate numbers of supporting staff will be available.

\section{Accommodation}

The job description should state where the consultant will have his office. The consultant requires a room of his own which if he chooses to use it for supervision should be sufficiently large to accommodate that purpose. The furnishings of the office and of any therapy rooms should reflect the nature of psychotherapy and provide an informal and personal setting.

\title{
Stop Press: Eli Lilly Lecture
}

The first of an annual series of lectures to be sponsored by Eli Lilly Co. Ltd. will be held on 5 February 1985 at the Winter Quarterly Meeting of the College. The lecture will be delivered by Dr Seymour Kety on the subject 'Recent Contributions of Neuroscience to an Understanding of Mental Disorder'. 